\title{
'Special Issue SHE' - The construction of a reasoned explanation of a health phenomenon: an analysis of competencies mobilized
}

\author{
Cláudia Faria; Sofia Freire; Mónica Baptista; Cecília Galvão \\ Institute of Education, University of Lisbon, Portugal \\ cbfaria@ie.ul.pt
}

\begin{abstract}
Mobilizing scientific knowledge for understanding the natural world and for critically appraise socio scientific situations and make decisions are key competencies for todays' society. So it is essential to understand how students at the end of compulsory schooling use scientific knowledge for understanding the surrounding world. The objective of this study is to understand how students construct a scientifically oriented explanation while making sense of a phenomenon related to health. We analysed 526 answers to a question of a Portuguese national $9^{\text {th }}$ grade science exam. The results reveal that most students present difficulties in explaining a phenomenon related to health supported by logical and clear reasoning, and in mobilizing scientific knowledge for connecting different scientific domains. We reaffirm the need to reconceptualise the role of health education within science education. Developing reading, writing and discussion activities related to health, which requires the use of scientific knowledge from different domains, would facilitate students' understanding and appropriation of scientific knowledge and its transference. This is a fundamental competence for promoting active and informed citizenship.
\end{abstract}

Running-head: Creating a reasoned explanation in science classes

This is an electronic version of an article published in Faria, C, Freire, S., Baptista. M. \& Galvão, C. (2014). The construction of a reasoned explanation of a health phenomenon: an analysis of competencies mobilized. International Journal of Science Education, 36(9): 1476-1490. DOI: 10.1080/09500693.2013.783723 


\section{Introduction}

We live in a complex, ever changing world, in which science occupies a hegemonic position and where limits of science are less circumscribed to the natural world and to the world of scientists. Indeed, scientists are increasingly being called to find solutions for problems that emerge within the society. Besides many proposed solutions have impacts on society, and as such citizens are increasingly being challenged to critically appraise and to make informed decisions concerning those solutions (Driver, Leach, Millar \& Scott, 1996; Millar \& Osborne, 1998). So, more than ever science education should occupy a central position in the curriculum, seeking to improve citizens' abilities to use scientific knowledge to make informed decisions about personal and social issues (Lederman, 2006), such as environment and health. According to recent trends, in order to accomplish these major goals, science curricula should be restructured seeking to value the interconnections between science, health and society (Dillon, 2012; Gough, 2002). In particular, students should improve their understanding of risk and probability and should learn to appreciate the values implicit in a range of scientific, environmental and health issues (Dillon, 2012; Grace \& Ratcliffe, 2002) while using scientific evidence and data for supporting their reasoning.

Current society widely recognizes that health must be under the control of the individual citizen (WHO, 1986). As stated in the Ottawa Declaration (WHO, 1986), "health promotion is the process of enabling people to increase control over, and to improve, their health. To reach a state of complete physical, mental and social well-being, an individual or group must be able to identify and to realize aspirations, to satisfy needs, and to change or cope with the environment" (p.1). So, nowadays citizens are expected to critically appraise issues related to 
their health and to make informed decisions concerning lifestyle and healthy behaviours. Science education can play a significant role in developing some competencies, such as critical thinking and scientific reasoning (European Commission, 2007; Keselman, Kaufman \& Patel, 2004). Furthermore, by equipping citizens with these competencies, science education will facilitate the breaking away with routine and non-thoughtful ways of analysing situations related to health, while enacting more sophisticated ways of understanding those situations (European Commission, 2007).

In Portugal, improving students' scientific knowledge in order to understand issues related to health and to make informed decisions about their lifestyle are important goals of the Science curriculum of basic education (DEB, 2001; Galvão et al., 2002). Indeed, intentional goals of the Portuguese Science curriculum are: to understand basic scientific concepts related to health, to develop positive attitudes concerning health, to acknowledge the importance of developing healthy habits and behaviours as well as to critically recognize the effect that biological, social, cultural, scientific and technologic dimensions have on healthy habits and behaviours.

Considering the importance of empowering students to make informed decisions about situations related to health, the goal of this study is to understand how students at the end of compulsory schooling construct a scientifically oriented explanation of a phenomenon related to health. Furthermore, considering the results obtained, we aim with this paper to add to the recent discussion concerning the proposed need of establishing a dialogue between science, environment and health education (Dillon, 2012).

This is an electronic version of an article published in Faria, C, Freire, S., Baptista. M. \& Galvão, C. (2014). The construction of a reasoned explanation of a health phenomenon: an analysis of competencies mobilized. International Journal of Science Education, 36(9): 1476-1490. DOI: 10.1080/09500693.2013.783723 


\section{Theoretical framework}

Several studies reveal that students have reduced interest with school science and science careers, as well as underdeveloped scientific knowledge and key competencies (European Commission, 2007), which limit their understanding of natural phenomenon, and reduce their ability to critically appraise social situations and to make informed choices concerning complex socio scientific issues. Many obstacles have been pointed to explain this state of affairs.

Science is a specific type of knowledge, which is based on socially constructed and validated constructs for interpreting phenomena and based on practices developed within communities of practice (Driver, Newton \& Osborne, 2000; Lederman, 2006; Simon, Erduran \& Osborne, 2006). According to Duschl and Osborne (2002), science "has particular ways of considering evidence; generating, testing, and evaluating theories; and communicating ideas" and as a result "learning scientific inquiry requires immersion into the language, culture, and tools of scientific activity - a language and culture that is founded in certain logical and epistemological values that make science different from other ways of knowing" (p. 45). So, in order to learn science, students have to develop an entirely new understanding about scientific ways of knowing (Leach \& Scott, 1995) and they have to learn the language of science (Wellington \& Osborne, 2001), and this is not an easy task, due to the specific characteristics of this language (lexically dense, specific syntax, multiple genres, multiple semiotic-modes, logical connectives, natural concepts acquiring new meanings, its cumulative character) (Lemke, 2003). So, one main obstacle for developing scientific reasoning and a deep understanding of science and about science is related to the difficulty of understanding the scientific ways of knowing (Leach \& Scott, 1995).

This is an electronic version of an article published in Faria, C, Freire, S., Baptista. M. \& Galvão, C. (2014). The construction of a reasoned explanation of a health phenomenon: an analysis of competencies mobilized. International Journal of Science Education, 36(9): 1476-1490. DOI: 10.1080/09500693.2013.783723 
Another main obstacle emerges from everyday use of scientific ideas. Indeed, in the course of their daily action, citizens constantly appropriate and use scientific knowledge for understanding and acting on their surrounding world. However, most often they focus their attention on details, not considering the whole, and they do not analyse that information using a scientific ground (European Commission, 2007). From a psychological point of view, when people meet an unfamiliar theoretical object, they use familiar knowledge in order to anchor the new knowledge (Abric, 1996; Moscovivi, 1989). Additionally, they select pieces of the new knowledge; they decontextualize it and rearrange it into a new coherent whole (Abric, 1996). This process allows transforming the abstract and intangible object of knowledge (such as a scientific concept or a scientific theory) into something more concrete that can be explained (Stewart \& Lacassagne, 2005). So, when an idea and/ or a theory passes from the world of science into the world of common sense, it is refracted (Farr, 1993) and transformed, affecting in a particular way citizens' understanding about the reality and their behaviour and decision making (Rangel, 1997; Moscovici, 1989; Wagner et al., 1999, 2000).

Therefore, for developing a deep understanding of and about science students have to break away with their common sense knowledge (Garrison \& Bentley, 1990; Leach \& Scott, 1995). This is not an easy process, as it implies that students learn to appreciate the scientific knowledge and its ways of knowing. Besides, it implies that students recognize it as one more knowledge system which can play an important role in particular interpersonal and social contexts and which has a specific communicative and meaning making function (Caravita, 2001; Castro, 2006; Driver et al., 1994). Leach and Scott (1995) state that "the challenge for the science teacher involves helping the students to make sense of scientific ways of knowing (2014). The construction of a reasoned explanation of a health phenomenon: an analysis of competencies mobilized. International Journal of Science Education, 36(9): 1476-1490. DOI: 10.1080/09500693.2013.783723 
in terms of their existing knowledge, and then to differentiate these two ways of knowing" (p. 49).

\section{Methods}

This particular study is part of a broader research project aimed at evaluating the Physics and Natural Sciences Curriculum of third cycle of Basic Education (13-15 years). In Portugal, the $9^{\text {th }}$ grade (15 years old) is the last year of basic education, at the end of which it is expected that all students have developed competencies of substantive, procedural and epistemological knowledge, reasoning and communication (Galvão, Reis, Freire \& Oliveira, 2007). So, among the various dimensions of the project, one is to identify which competencies students at the end of the $9^{\text {th }}$ grade have developed. In order to accomplish this goal, one of the tasks developed within the project was to collect and to analyse the students' answers to a national exam of natural sciences for the $9^{\text {th }}$ grade. Not all schools proved the answers for analysis and therefore a total of of 526 tests, from different regions of the country, were analysed.

In this paper, we present the results concerning the analysis of a specific complex open question requiring students to explain a phenomenon related to health. The main goal was to understand how students, at the end of compulsory schooling, construct a scientifically oriented explanation about a familiar subject related to human health.

The question under analysis was: "The decline of oestrogen contributes to an increment of bad cholesterol. At the menopause, there is a gradual cessation of ovarian cycle. Explain how the menopause contributes to an increased risk of Cerebral Vascular Accident (CVA)". The general topic, the menopause, is not explicitly addressed in science classes, but all the 
scientific concepts involved, such as ovarian cycle, hormones, cholesterol and CVA, are specific topics present in the science curriculum. The question is introduced with a text, contextualizing the topic. In order to present an explanation, students have to capture a sequence of causal and/ or correlational relations among different biological phenomena, as pictured in the next scheme (Figure 1). Besides, they have to integrate knowledge from two different scientific domains (the reproductive system and the circulatory system).

\section{- Insert figure 1 -}

So, in order to present an explanation, students have to: (1) associate the cessation of the ovarian cycle with the decline of oestrogen production $(a=» b)$; (2) recognize the fact, presented on the text, that the decline of oestrogen contributes to an increment of bad cholesterol and they have to use this fact $(b=» c)$; (3) based on their scientific knowledge, students have to associate bad cholesterol to an increased risk of Cerebral Vascular Accident $(c=» d)$. Finally, based on these partial relationships, students have to build an explanation that relates the menopause with increased risk of Cerebral Vascular Accident $(\mathrm{a} \ll=» d)$.

In order to analyze the quality of the explanation, we considered the type of language used (scientific versus common sense language) as well as the following competencies:

(1) Identifying relevant information (i.e., student identifies a and/or recognizes $b=» c$ and/or $\mathrm{c}=\gg \mathrm{d})$,

(2) Understanding scientific concepts and being able to use it for explaining a natural phenomenon (i.e., student uses scientific concepts for explaining relations between biological phenomena: $\mathrm{a}=\gg \mathrm{b}$ and/ or $\mathrm{c}=\gg \mathrm{d})$,

This is an electronic version of an article published in Faria, C, Freire, S., Baptista. M. \& Galvão, C. (2014). The construction of a reasoned explanation of a health phenomenon: an analysis of competencies mobilized. International Journal of Science Education, 36(9): 1476-1490. DOI: 10.1080/09500693.2013.783723 
(3) Integrating knowledge from two different scientific domains (reproductive system and the circulatory system) (i.e. student uses knowledge for sustaining the relation between a and d)

After analysing each answer, researchers built and used a dichotomous key (Figure 2), for categorizing students' according to the quality of explanation presented.

- $\quad$ Insert figure 2 -

The categorization process was performed independently by two researchers (co-authors of the present work). Afterwards, they discussed and, when needed, they reviewed the categorization in order to ensure that the groups are reliable.

Finally, the strategies students used for overcoming difficulties related to the integration of both scientific domains were analysed.

\section{Results}

From the 526 tests, $25 \%$ of students $(n=134)$ didn't answer the specific question under analysis. So, the following results concern the answers of 394 students. These answers reflect different levels of proficiency for explaining a phenomenon related to health, considering the competencies that were mobilized and the type of language used. Students' answers were grouped according to five groups (table 1).

- Insert table 1 -

This is an electronic version of an article published in Faria, C, Freire, S., Baptista. M. \& Galvão, C. (2014). The construction of a reasoned explanation of a health phenomenon: an analysis of competencies mobilized. International Journal of Science Education, 36(9): 1476-1490. DOI: 10.1080/09500693.2013.783723 


\section{Type of language and competencies mobilized}

- Group 1 [formed by $15 \%$ of students $(n=59)]$. Students from this group did not explain how the menopause and CVA are associated. They were not able to identify relevant information presented in the introductory text and so they didn't use it for answering the question. Their answer consisted of a number of common-sense beliefs and knowledge related to the menopause. For instance, some students wrote,

"At the menopause a woman stops having the menstruation. Women have many more psychological risks which may lead to an increased risk of stroke."

"Hormones are not produced and so, it can have consequences for women...It can affect the brain and usually they get dizzy, accumulated stress and so on... So, they can have a CVA."

"When a woman with high level of cholesterol enters the menopause, blood doesn't leave of the body and accumulates around in the brain, causing a CVA."

As highlighted by these examples, students were not able to use the given information (that the decline of oestrogen contributes to an increment of bad cholesterol) and, based on this they were not able to explore which other biological information could be useful for making sense of the relation between the menopause and an increased risk of CVA (e.g., cessation of the ovarian cycle, decrease in hormone production, bad cholesterol and CVA).

This is an electronic version of an article published in Faria, C, Freire, S., Baptista. M. \& Galvão, C. (2014). The construction of a reasoned explanation of a health phenomenon: an analysis of competencies mobilized. International Journal of Science Education, 36(9): 1476-1490. DOI: 10.1080/09500693.2013.783723 
Mention should be made that these students communicated their ideas using mainly commonsense language. Yet some of them used words such as cholesterol, hormones, oestrogen, CVA, psychological risks. These words originate within the domain of science but they have a high penetration on common sense discourse; other words, such as oestrogen were presented on the exam. They used these words in a way that do not reveal scientific understanding (for instance, psychological risks are associated to risk of stroke; lack of hormones production is associated to dizziness, to accumulated stress; the menopause is associated with accumulation of blood in the body and CVA is associated with the accumulation of blood in the brain).

- Group 2 [representing $10 \%$ of the students $(n=39)$ ] was formed by students who did not explain how the menopause and CVA are associated, but conversely to group 1, they were able to identify some significant information (such as ovarian cycle, hormones production, bad cholesterol and risk of CVA) for answering, as the following examples illustrate.

"[The menopause contributes to an increased risk of CVA] as the production of hormones increases and body fat also increases. So blood clots are formed. They block the arteries, preventing the blood reaching the brain thus causing a CVA"

\begin{abstract}
"At the menopause there is a progressive stopping of the ovarian cycle. With the reduction of oestrogen, the person is willing to eat more. And also to eat less quality food. This contributes to the increment of bad cholesterol. This behaviour can, at worst, contribute to an increased risk of CVA".
\end{abstract}

This is an electronic version of an article published in Faria, C, Freire, S., Baptista. M. \& Galvão, C. (2014). The construction of a reasoned explanation of a health phenomenon: an analysis of competencies mobilized. International Journal of Science Education, 36(9): 1476-1490. DOI: 10.1080/09500693.2013.783723 
"As the decrease of oestrogen production contributes to an increase of bad cholesterol, and as at the menopause, we observe that oestrogen and progesterone production stops, there is an increased risk of CVA".

Despite identifying important biological information, students from this group could not explain the relation between some of the phenomena that they identified: Why does hormones production increase during the menopause? Or correctly, why do they decrease? What is the consequence of the cessation of the ovarian cycle? Why at the menopause there is an increment of the body's fat? Their answers relied mostly on their common-sense knowledge and they display a confusing reasoning, which is not scientifically grounded. For instance, why does the decrease of oestrogen production imply eating more and less quality food? How can this relation be explained? And what does "to eat less quality food" mean?

- Group 3 is formed by $17 \%$ of the students $(n=67)$, who, as the previous groups, were not able to explain how the menopause and an increased risk of CVA are associated. However, they were able to identify some information concerning relevant biological phenomena (namely the menopause and decline of oestrogen, bad cholesterol and an increased risk of CVA) and they were able to explain those phenomena, using scientific concepts. Examples of this type of answer are illustrated by the following excerpts,

"As stated in the text, the decline of oestrogen contributes to an increment of bad $\underline{\text { cholesterol. As at the menopause ovarian cycle stops, as a result oestrogen production }}$ decreases. As bad cholesterol contributes for increasing the risk of CVA, so women entering the menopause will have more probabilities of having a CVA".

This is an electronic version of an article published in Faria, C, Freire, S., Baptista. M. \& Galvão, C. (2014). The construction of a reasoned explanation of a health phenomenon: an analysis of competencies mobilized. International Journal of Science Education, 36(9): 1476-1490. DOI: 10.1080/09500693.2013.783723 
"The menopause contributes to the increased risk of CVA in this way: $\underline{\text { if the decline of }}$

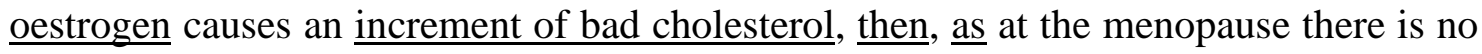
more production of oestrogen as the ovarian cycle is stopped, women entering the menopause will be more at risk of a CVA than those women that are still menstruating”.

This answer reveals that students' understand what the menopause is by associating it to the cessation of ovarian cycle and to the decrease of oestrogen production. But what is the relation between bad cholesterol and CVA? Students cannot integrate the connection between the menopause and the risk of CVA. Other students focus their attention on the consequences of bad cholesterol, as illustrated by this example, which is scientifically incorrect,

"The menopause is a gradual cessation of ovarian cycle. The production of the female hormone decreases. This will cause the bad cholesterol, which will attack the heart, as it increases the amount of fat in the veins and arteries."

So, despite revealing understanding of scientific concepts, these students were not able to explain the relationship between the menopause and CVA.

- Students from group 4 [representing $24 \%$ of the students $(n=95)$ ] were able to explain how the menopause and an increased risk of CVA are associated. They identified relevant information; they were able to use scientific concepts for explaining the relationship between the menopause and the cessation of the ovarian cycle, as well as cholesterol and the risk of (2014). The construction of a reasoned explanation of a health phenomenon: an analysis of competencies mobilized. International Journal of Science Education, 36(9): 1476-1490. DOI: 10.1080/09500693.2013.783723 
CVA. However, despite revealing comprehension of the phenomena and despite using scientific concepts for explaining the ovarian cycle and oestrogen production, oestrogen and bad cholesterol, and bad cholesterol and risk of CVA, they relied on a common-sense language and knowledge to relate the menopause with an increased risk of CVA, as illustrated by the following examples.

"The menopause contributes to an increased risk of CVA, as at the menopause oestrogen decreases which contributes to the increase of bad cholesterol. Cholesterol is when we observe an accumulation of fat on the arteries. As such, the blood has difficulty passing, "hardly" arriving at the brain. This decline of oestrogen will worsen the situation".

"Bad cholesterol results from the accumulation of fats in the blood that inhibits blood movement. The blood has to go through all cells, especially in the brain. If it does not, the brain cells can die (CVA). This happens because women at the menopause, stop producing oestrogen”.

For explaining the relation between the menopause and the increased risk of CVA, they use common-sense ideas (such as, fats in the blood inhibit blood movement, blood goes through cells, cholesterol as an accumulation of fat in the arteries) and language (e.g. blood "hardly" arrives at the brain).

- Finally, 34\% of the students $(n=134)$ were categorized on the group 5. These students were able to provide a scientifically oriented explanation for the problem, acknowledging the (2014). The construction of a reasoned explanation of a health phenomenon: an analysis of competencies mobilized. International Journal of Science Education, 36(9): 1476-1490. DOI: 10.1080/09500693.2013.783723 
menopause and the risk of CVA as two phenomena, which are connected through a complex chain of causal phenomena. So they were able to identify relevant information, to partially explain biological phenomena using scientific concepts and finally to integrate knowledge from two different scientific domains (reproductive system and circulatory system). Their final explanation was based on scientific knowledge. However, mention should be made that in some of the cases, final answers' were still incorrect or incomplete. The following examples illustrates this type of answer,

\begin{abstract}
"During the menopause the ovarian cycle will gradually stop. Consequently, the oestrogen is no longer produced. Bad cholesterol increases, blocking the veins and arteries, hindering blood circulation. As no blood reaches the brain, it does not get enough oxygen and a stroke can occur."
\end{abstract}

\begin{abstract}
"During the menopause there is a progressive cessation of ovarian cycle, due to a progressive decrease of oestrogen. This decrease contributes to bad cholesterol, which contributes to the deposition of fat on the arteries, making blood circulation difficult. This can even lead to a total obstruction of the vessel. When this obstruction occurs on the arteries that transport the blood to the brain, a CVA follows. So, the menopause facilitates occurrence of CVA".
\end{abstract}

Both examples show how students used logical connectives (due; when this... then that; so; as... then...; consequently) (Halliday \& Martin, 1993) and causal verbs (e.g. to lead, to contribute) for exploring causal relations between different phenomena.

This is an electronic version of an article published in Faria, C, Freire, S., Baptista. M. \& Galvão, C. (2014). The construction of a reasoned explanation of a health phenomenon: an analysis of competencies mobilized. International Journal of Science Education, 36(9): 1476-1490. DOI: 10.1080/09500693.2013.783723 


\section{Difficulties and strategies for overcoming it}

One important dimension of the question is that it demands from the students articulating knowledge from two different scientific domains (reproductive system and circulatory system). Many students faced difficulties in articulating knowledge from these two domains as evidenced by their answers. Indeed, most students focused their attention on only one of the biological phenomena (either ovarian cycle and oestrogen production or bad cholesterol and risk of CVA). Furthermore, many students did not recognize the evidence provided in the exam (that the decline of the oestrogen production is related to an increment of bad cholesterol) or they did not use it to connect the two different scientific domains.

In order to deal with this difficulty, students used two different strategies:

(i) Some students introduced new information, such as "Increment of bad cholesterol is due to inadequate nutrition and/or lack of physical exercise". So, as evidenced in the example above, for justifying the increment of cholesterol in the blood, these students ignored or devalued the relation between oestrogen and cholesterol, and instead they mobilized previous knowledge (either common-sense or scientific);

(ii) Other students built a short-cut between the first phenomenon (ovarian cycle and oestrogen production) and the last one (bad cholesterol and risk of CVA) for explaining how the menopause is associated with an increased risk of CVA. In their explanation, they established some connections between the menopause and CVA, but they ignored the evidence provided in the exam (that the decrease of oestrogen contributes to an increment of bad cholesterol). The following excerpt illustrates this type of strategy: "Any imbalance in

This is an electronic version of an article published in Faria, C, Freire, S., Baptista. M. \& Galvão, C. (2014). The construction of a reasoned explanation of a health phenomenon: an analysis of competencies mobilized. International Journal of Science Education, 36(9): 1476-1490. DOI: 10.1080/09500693.2013.783723 
the body causes diseases. If the ovarian cycle stops, it causes an imbalance in the body, so it causes a disease, like CVA.”

These strategies highlight how students were able to overcome their difficulty with transferring knowledge from different contexts and with applying new knowledge to new situations. This was so even considering students who were able to propose an explanation. Indeed, mention should be made that both strategies for dealing with the difficulty of integrating the two different scientific domains were common to all five groups.

\section{Discussion and Conclusion}

The results obtained reveal that some students were able to explain how the menopause and the increased risk of CVA are associated, identifying the relevant information, exploring the relationships between biological phenomenon and explaining a chain of successive causal relations between them. These were the students from group five and four. Students from both groups reveal a systemic understanding of the overall phenomenon, as they understand how each part affects each other, and how these relationships affect the whole. However, both groups differed concerning the type of language used.

Indeed, students from group five relied mainly on scientific concepts learnt previously and they were able to use them for explaining the situation related to health. Furthermore they were able to understand and to use basic scientific concepts for making sense of the relation between menopause and CVA which is not explicitly addressed at science classes. This is an important goal of science education: that students are able to use scientific knowledge for making sense of daily situations and issues. In comparison, for explaining how the 
menopause and the increased risk of CVA are associated, group four used a "hybrid language", i.e., these students used scientific and everyday concepts and terms in an interchangeable way. They seem to understand scientific concepts within a very limited context. So when required to use scientific concepts for making sense of a situation that goes beyond topics addressed in the classroom, these students have difficulties in using those scientific concepts. As such they avail of what is most familiar to them.

Another important result concerns those students who were not able to provide a scientific oriented explanation, supported by logical and clear reasoning. Their answers were a sequence of statements, often with a scientific basis, but without any relation between them, or in other cases, their answers were a set of common sense beliefs, obeying more or less to a logical sequence.

Concerning these groups, we observed that some difficulties derived from students' inability to identify relevant information, understand scientific concepts and use scientific knowledge. These were the students from group one. In other cases, despite identifying relevant information from the introductory text, students did not use scientific knowledge to make sense of that information. These were the students from group two. What is the nature of these difficulties? It may be a disinterest in science topics that do not engage them sufficiently so that they are unwilling to spend time and effort in answering the question fully? Or is it a question of not understanding a specific language and a specific statement, which is a complex one, not only because of the knowledge required, but also because of the nature of the statement itself? Mention should be made that the menopause is not a topic explicitly addressed in science classes. However, according to the Portuguese science (2014). The construction of a reasoned explanation of a health phenomenon: an analysis of competencies mobilized. International Journal of Science Education, 36(9): 1476-1490. DOI: 10.1080/09500693.2013.783723 
curriculum, students are expected to learn some scientific concepts in order to analyse general situations related to daily life (DEB, 2001; Galvão et al., 2002). Students from both groups do not reveal an understanding of some scientific concepts and, decidedly, they do not use it to make sense of a complex phenomenon related to health.

In what concerns group three, results reveal that students were able to identify relevant information. Besides, they used scientific knowledge for making sense of that information, revealing understanding of scientific concepts. However, they were not able to build a scientifically coherent explanation for the overall phenomenon. These students were able to interpret the text, to use meaningfully some of the information given and even to use scientific knowledge. However, they lack systemic reasoning. They present immediate and disconnected explanations, using scientific concepts derived from a very restrictive meaning context. They cannot apprehend the whole phenomenon, consider each parts individually and then relate it all again into a coherent whole. Is it a case of not being used to this kind of reasoning? Is it a case of having learnt scientific concepts mechanically and so of being able to use it only in very restricted situations?

Despite the difference amongst the three groups, results obtained still make us wonder whether these students are able to critically reflect and scientifically reason about health issues, one of the intentional goals of the Portuguese science curriculum (DEB, 2001; Galvão et al., 2002). Indeed, one important goal of science education is to improve citizens' abilities to use scientific knowledge to make informed decisions about personal and social issues (Lederman, 2006). In order to achieve this goal, students have to become aware that different knowledge systems do co-exist; they have to get familiar with the scientific knowledge (2014). The construction of a reasoned explanation of a health phenomenon: an analysis of competencies mobilized. International Journal of Science Education, 36(9): 1476-1490. DOI: 10.1080/09500693.2013.783723 
system and to recognize the role that it can play for building meaning within particular interpersonal and social contexts (Caravita, 2001; Castro, 2006; Driver et al., 1994). However, the results obtained suggest that these students still rely in their common sense knowledge for making sense of situations related to health, due to different reasons.

One final important finding is related with the difficulties that the majority of the students revealed with integrating different scientific domains (reproductive system and circulatory system). Students do not understand the relationship between the decline of oestrogen and the increment of bad cholesterol, and so they devalue this evidence and rely on familiar knowledge for explaining it. This difficulty make us wonder whether science teaching is still very disciplinary, not promoting an integration of the different scientific subjects and as such not facilitating the transference of (disconnected) learned knowledge for making sense of complex unfamiliar situations.

Considering the overall results, we are faced with the question of how teachers can create learning situations that require from students understanding scientific knowledge and using it for exploring new possibilities in thinking and for building meaning.

Brown and Kyuu (2008) argue for a "content-first" approach to teaching science. According to this approach, firstly everyday language is used to introduce the ideas associated with scientific content. Then teacher proceeds with direct language instruction with the goal of demonstrating the synergy between every day and scientific descriptions of phenomena. According to the authors, this type of approach yields greater conceptual understanding. However, for the accomplishment of this approach, teachers must be successful in providing (2014). The construction of a reasoned explanation of a health phenomenon: an analysis of competencies mobilized. International Journal of Science Education, 36(9): 1476-1490. DOI: 10.1080/09500693.2013.783723 
students' with instructional supports that will help them converting everyday language into scientific one. For accomplishing that, teachers must introduce students to the language of the content by providing opportunities to use detailed scientific language (Brown, 2004, 2006; Brown \& Ryuu, 2008; Reveles, Cordova \& Kelly, 2002) and they have to require from the students to integrate the scientific concepts and terms into their vocabulary through classroom talk and written assignments.

However, as science education seeks much more then to simply make students able to talk about topics using scientific words, it is essential to create learning situations that not only facilitate the appropriation of correct scientific concepts, but also that promotes its use in logical argumentation, in explaining a natural phenomenon or in making sense of socio scientific situations.

Keselman and col. (2004) emphasize the importance of conceptual understanding for evaluating information, which inform decisions about health. Accordingly, Grace and Ratcliff (2002) mention that in evaluating questions related to conservation issues, students base their thinking in their own values and scientific knowledge and as a result it is important to create learning situations that not only facilitate decision making based on values and attitudes, but also based on scientific data that students know and understand. Grooms (this special issue) in a study about the effectiveness of argument-based lab activities for supporting the construction of arguments concerning socio scientific issues, found that science students who were involved in the argument-based activities were able to craft higher quality arguments, than students who followed a more traditional course. According to this author, using scientific evidence for supporting argumentation is a skill that can be transferred for (2014). The construction of a reasoned explanation of a health phenomenon: an analysis of competencies mobilized. International Journal of Science Education, 36(9): 1476-1490. DOI: 10.1080/09500693.2013.783723 
analysing other daily issues, namely environmental and health issues. So developing classroom argument-based activities might be a good strategy for facilitating students' use of scientific knowledge for reasoning.

Considering the previous discussion as well as the results obtained in the present study, we reaffirm the need to re-conceptualize the role of health education within science education (Dillon, 2012) and to enhance the trans-disciplinary dialogue between science, environment and health (Zeyler \& Dillon, this special issue). Developing reading, writing and discussion activities related to health, which requires that students use scientific knowledge from different domains in order to make sense of those topics, would facilitate students' understanding and appropriation of scientific knowledge and its transference. This is a fundamental competence for promoting an active and informed citizenship.

One final word in what concerns the context. Students' mobilization of scientific knowledge was analyzed in a formal context of school assessment. Within this context, students know that they are supposed to use their school-knowledge. But one question persists: Students, at least those students from group five, learnt to use scientific knowledge and language in a formal classroom context but will they use it in the daily context? Would they use scientific knowledge for making sense of everyday issues like the menopause and CVA, in a context of everyday life or decision making? This is an issue that deserves further investigation, as students are constantly being called to deal with information concerning healthy habits and behaviours, in their daily lives, and scientific knowledge can be a solid ground for students to understand their options and hopefully to help them to make informed decisions (Keselman, et al., 2004).

This is an electronic version of an article published in Faria, C, Freire, S., Baptista. M. \& Galvão, C. (2014). The construction of a reasoned explanation of a health phenomenon: an analysis of competencies mobilized. International Journal of Science Education, 36(9): 1476-1490. DOI: 10.1080/09500693.2013.783723 


\section{Acknowledgements}

Part of this study was supported by Fundação para a Ciência e a Tecnologia as part of the Project "Evaluation of the Physics and Natural Sciences Curriculum, third cycle of Basic Education" (PTDC/CPE-CED/102789/2008).

\section{References}

Abric (1996). Specific processes of social representations. Papers on social Representations, 5(1), 77-80.

Brown, B. (2004). Discursive identity: Assimilation into the culture of science and its implications for minority students. Journal of Research in Science Teaching, 41(8), $810-834$.

Brown, B. (2006). “It isn't no slang that can be said about this stuff”: Language, identity, and appropriating science discourse. Journal of Research in Science Teaching, 43(1), 96-126.

Brown, B.A., \& Ryoo, K. (2008). Teaching Science as a Language: A "Content-First' Approach to Science Teaching. Journal of Research in Science Teaching, 45(5), 529553.

Castro, P. (2006). Applying Social Psychology to the Study of Environmental Concern and Environmental Worldviews: Contributions from the Social Representations Approach. Journal of Community \& Applied Social Psychology, 16, 247-266.

Caravita, S. (2001) A re-framed conceptual change theory? Learning and Instruction, 11, $421-429$.

This is an electronic version of an article published in Faria, C, Freire, S., Baptista. M. \& Galvão, C. (2014). The construction of a reasoned explanation of a health phenomenon: an analysis of competencies mobilized. International Journal of Science Education, 36(9): 1476-1490. DOI: 10.1080/09500693.2013.783723 
Departamento Educação Básica [DEB] (2001). Currículo Nacional do Ensino Básico Competências Essenciais. Lisboa, Ministério da Educação.

Dillon, J. (2012). Science, environment and health education: towards a reconceptualisation of their mutual interdependences. In A. Zeyer and R. Kyburz-Graber (Ed.). ScienceEnvironment-Health. Towards a renewed pedagogy for science education (pp. 87-101). Dordrecht: Springer.

Driver, R., Asoko, H., Leach, J., Mortimer, E., \& Scott, P. (1994). Constructing scientific knowledge in the classroom. Educational Researcher, 23(7), 5-12.

Driver, R., Leach, J., Millar, R., \& Scott, P. (1996). Young People's Images of Science. Buckingham, Open University Press.

Driver, R., Newton, P., \& Osborne, J. (2000). Establishing the norms of scientific argumentation in classrooms. Science Education, 84, 287-312.

Duschl, R. A., \& Osborne, J. (2002). Supporting and promoting argumentation discourse in science education. Studies in Science Education, 38, 39-72.

European Commission (Eds.) (2007). Science Education Now: A Renewed Pedagogy for the Future of Europe. Brussels, author.

Farr, R. (1993). Theory and method in the study of social representations. In G. Breakwell, \& D. Canter (Eds.) Empirical approaches to social representations (pp. 15-38). Oxford, Clarendon Press.

Galvão, C. (Coord.), Neves, A., Freire, A.M., Lopes, A.M., Santos, M.C., Vilela, M.C., Oliveira, M.T. \& Pereira, M. (2002). Ciências Físicas e Naturais. Orientações curriculares para o $3^{\circ}$ ciclo do ensino básico. Lisboa: Ministério da Educação, Departamento da Educação Básica.

Galvão, C., Reis, P., Freire, A., \& Oliveira, T. (2007). Science curriculum in Portugal: From the development to the evaluation of students' competences. In D. Waddington, P. (2014). The construction of a reasoned explanation of a health phenomenon: an analysis of competencies mobilized. International Journal of Science Education, 36(9): 1476-1490. DOI: 10.1080/09500693.2013.783723 
Nentwig, \& S. Schanze (Eds.) Making it comparable. Standards in Science Education (pp.237-253). Münster, Waxmann.

Garrison, J., \& Bentley, M. (1990). Science education, conceptual change and breaking with everyday experience. Studies in Philosophy and Education, 10(1), 19-35.

Gough, A. (2002). Mutualism: A different agenda for environmental and science education. International Journal of Science Education, 24(11): 1201-1215.

Grace, M.M., \& Ratcliffe, M. (2002). The science and values that young people draw upon to make decisions about biological conservation issues. International Journal of Science Education, 24, 1157-1169.

Grooms, J. (in prep). Using a Science Laboratory Course to Enhance Undergraduate Students' Arguments about Socioscientific Issues related to the Environment and Personal Health. International Journal of Science Education (Science|Environment|Health - special issue).

Halliday, M.A.K., \& Martin, J.R. (1993). Writing science: Literacy and discursive power. London, Falmer Press.

Keselman, A., Kaufman, D.R., \& Patel, V.L. (2004). "You can exercise your way out of HIV" and other stories: The role of biological knowledge in adolescents' evaluation of myths. Science Education, 88(4), 548-573.

Leach, J., \& Scott, P. (1995) The demands of learning science concepts: issues of theory and practice. School Science Review, 76, 47-51

Lederman, N.G. (2006). Syntax of the nature of science within inquiry and science instruction. In L.B. Flick, \& N.G. Lederman (Eds.) Scientific inquiry and nature of science. Implications for teaching, learning, and teacher education (pp. 301-318). Dordrecht, Springer.

This is an electronic version of an article published in Faria, C, Freire, S., Baptista. M. \& Galvão, C. (2014). The construction of a reasoned explanation of a health phenomenon: an analysis of competencies mobilized. International Journal of Science Education, 36(9): 1476-1490. DOI: 10.1080/09500693.2013.783723 
Lemke, J.L. (2003). Teaching all the languages of science: Words, symbols, images and $\begin{array}{lll}\text { actions. } & \text { Retrieved http://www- }\end{array}$ personal.umich.edu/ jaylemke/papers/barcelon.htm.

Millar, R., \& Osborne, J. (1998). Beyond 2000: Science education for the future. London, Kings College.

Moscovici, S. (1989). Des représentation collectives aux représentation sociales. In D. Jodelet (Ed.) Les representations sociales (pp. 62-86). Paris, PUF.

WHO (1986). Ottawa Charter for Health Promotion First International Conference on Health Promotion. Ottawa, 21 November 1986 - WHO/HPR/HEP/95.1

Rangel, M. (1997). Representation of students, as a means of practical knowledge, and learning of scientific knowledge at school. Papers on Social Representations, 6(1), 5158.

Reveles, J., Cordova, R., \& Kelly, G. (2002). Science literacy and academic identity formulation. Journal of Research in Science Teaching, 41, 1111-1144.

Simon, S., Erduran, S. \& Osborne, J. (2006). Learning to Teach Argumentation: Research and Development in the Science Classroom. International Journal of Science Education, 28 (2-3), 235-260.

Stewart, S., \& Lacassagne, M.-F. (2005). Social representations as a diagnostic tool for identifying cultural and other group differences. Psychology and Marketing, 22(9), 721-738.

Wagner, W., Duveen, G., Farr, R., Jovchelovitch, S., Lorenzi-Cioldi, F., Marková, I., \& Rose, D. (1999). Theory and method of social representations. Asian Journal of Social Psychology, 2, 95-125

This is an electronic version of an article published in Faria, C, Freire, S., Baptista. M. \& Galvão, C. (2014). The construction of a reasoned explanation of a health phenomenon: an analysis of competencies mobilized. International Journal of Science Education, 36(9): 1476-1490. DOI: 10.1080/09500693.2013.783723 
Wagner, W., Duveen, G., Verma, J., \& Themel, M. (2000). I have some faith and at the same time I don`t believe|: Cognitive Polyphasia and Cultural Change in India. Journal of Community and Applied Social Psychology, 10, 301-314.

Wellington, J., \& Osborne, J. (2001). Language and literacy in science education. Buckingham, Open University Press.

Zeyler, A., Dillon, J. (in prep.). Science|Environment|Health - Towards a reconceptualization of three critical and inter-linked areas of education. Introduction. International Journal of Science Education (Science|Environment|Health - special issue).

This is an electronic version of an article published in Faria, C, Freire, S., Baptista. M. \& Galvão, C. (2014). The construction of a reasoned explanation of a health phenomenon: an analysis of competencies mobilized. International Journal of Science Education, 36(9): 1476-1490. DOI: 10.1080/09500693.2013.783723 
Table 1. Competencies mobilized and type of language used in constructing the explanation by students of the different groups.

\begin{tabular}{lcccc}
\hline & & Competencies & & Type of \\
& & & & language \\
& identify relevant & understand scientific & use scientific & scientific \\
& information & concepts & knowledge & language \\
\hline Group 1 & - & - & - & - \\
\hline Group 2 & + & - & - & + \\
\hline Group 3 & + & + & + & - \\
\hline Group 4 & + & + & + & + \\
\hline Group 5 & + & & & + \\
\hline
\end{tabular}

This is an electronic version of an article published in Faria, C, Freire, S., Baptista. M. \& Galvão, C. (2014). The construction of a reasoned explanation of a health phenomenon: an analysis of competencies mobilized. International Journal of Science Education, 36(9): 1476-1490. DOI: 10.1080/09500693.2013.783723 
Figure legends:

Figure 1. Causal or correlational relations among phenomena.

Figure 2. Dichotomous key for categorizing students' answers.

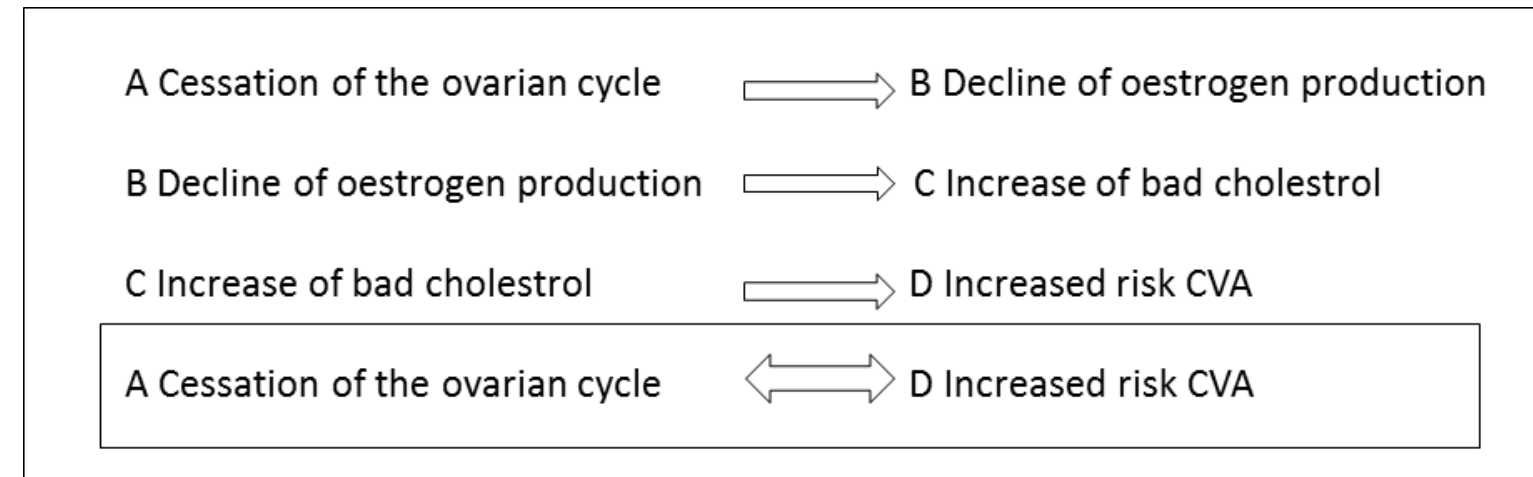

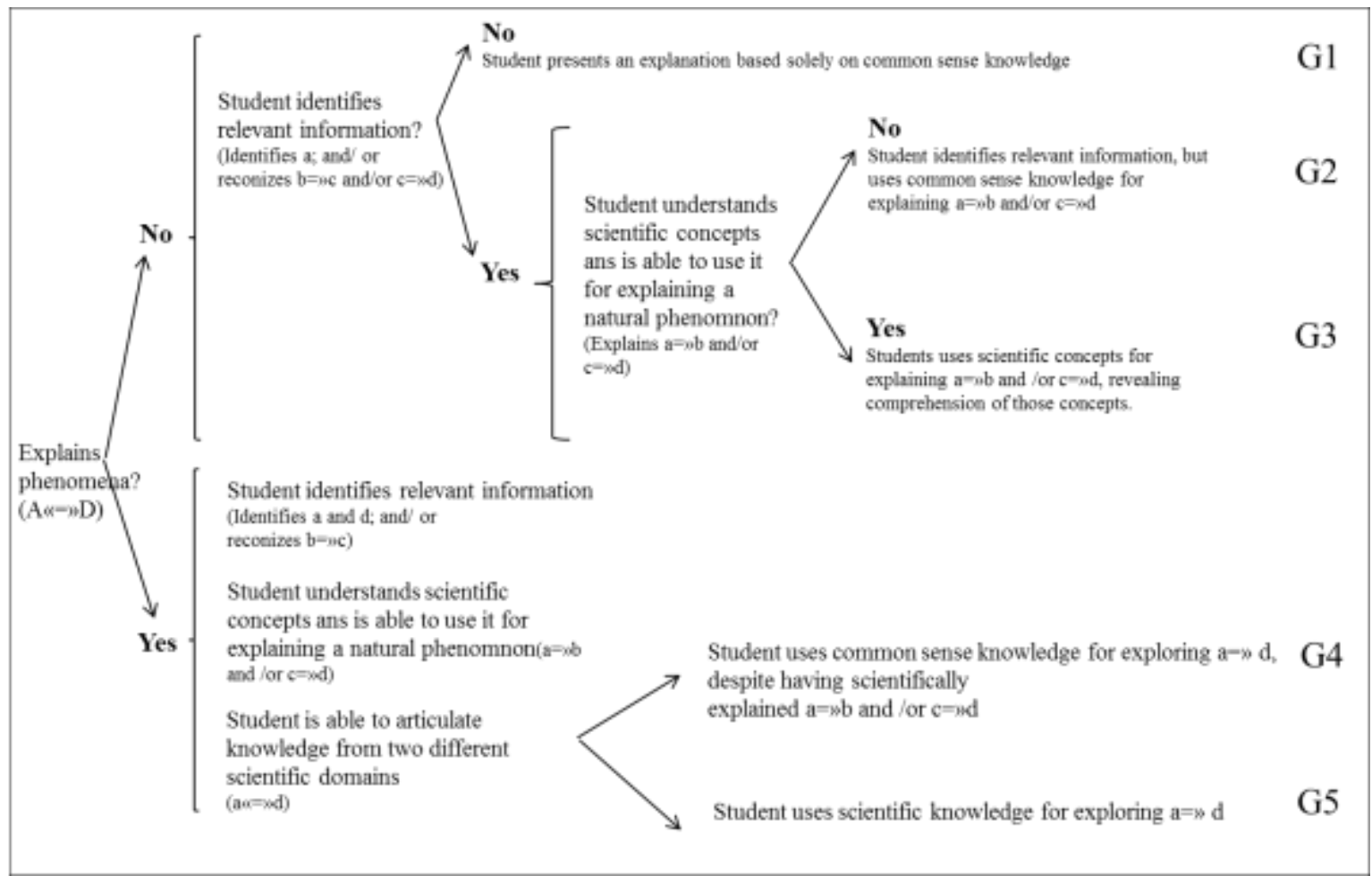

This is an electronic version of an article published in Faria, C, Freire, S., Baptista. M. \& Galvão, C. (2014). The construction of a reasoned explanation of a health phenomenon: an analysis of competencies mobilized. International Journal of Science Education, 36(9): 1476-1490. DOI: 10.1080/09500693.2013.783723 